\title{
LESS is more for the patient
}

\author{
Katherine Moore, MD, FRCSC \\ Division of Urology, CHU de Québec, Université Laval, Québec City, QC
}

See related article on page 48 .

Cite as: Can Urol Assoc J 2015;9(1-2):53-4. http://dx.doi.org/10.5489/cuaj.2733 Published online February 5, 2015.

K hambati and colleagues report the first Canadian series of laparo-endoscopic single site surgery (LESS) in the pediatric population. ${ }^{1}$ Laparoscopy on the pediatric population is often challenging due to limited space and almost non-exiting ergonomic positioning. Nonetheless, one experienced laparoscopist is still pushing the limits. Khambati and colleagues report their experience with several frequent pediatric procedures, such as the simple Palomo varicocelectomy to the more challenging pyeloplasty. ${ }^{1}$ Although the indications for surgery are heterogeneous, as are patients' size and age (range: 7.5-17.5 years), the authors demonstrate that LESS is widely applicable to different procedures performed by pediatric urologists. LESS may be extremely challenging even for the most experienced laparoscopist as the triangulation of the instruments and the usual positioning of the camera will both differ. Dry training in the laboratory is probably the best way to acquire the adequate hand-eye coordination to achieve surgical times comparable to those obtained for standard laparoscopic procedures.

LESS series are rapidly increasing in numbers in the literature. The reported procedures are becoming more complex with time, using different types of instruments and devices. ${ }^{2-4}$ It would be interesting to evaluate whether one specific access port is more suitable for pediatric cases. In the actual report, the authors used three different devices. Their report suggests that they preferred one specific access port as they used it in their latter cases. They typically used one straight and one articulated instrument of different lengths, in an attempt to prevent extracorporal clashing. This is combined with an articulated 5-mm camera that provided a $100^{\circ}$ angu- lation. This corroborates Sanchez-Margallo and colleagues' conclusion that using two articulated instruments impairs surgical easiness. ${ }^{5}$

Postoperative cosmetic appearance and limited puncture of the peritoneum are indisputable advantages of LESS. The barely visible umbilical scar will make it more difficult for physicians to recapitulate the patient surgical history from the physical examination, as it was previously possible. While the authors suggested that the requirement for narcotics and the length of the hospital stay will be lower with LESS, I doubt that this will be significant if analyzed in a prospective study as they both are already very low in the pediatric population. We know that our patients generally are more inconvenienced by the referred shoulder pain created by the peritoneal insufflation than by the pain secondary to each and single incisions. Khambati and colleagues clearly mentioned that their results are likely not reproducible by the standard pediatric urologist. ${ }^{1}$ This statement follows the European Association of Urology grade A recommendations on Robotic- and Single-site Surgery in Urology. ${ }^{3}$ Nevertheless, surgical time should be carefully monitored by beginners as neurotoxicity related to anesthesia is now widely reported. ${ }^{6}$ Complications should also be well-identified as some series suggest that they may be more prevalent when LESS is performed compared to standard laparoscopy. ${ }^{2,3}$

Finally, the present cohort demonstrates the safety and feasibility of transumbilical LESS in the pediatric urological population. Randomized studies are required to better define the usefulness of LESS as no demonstrated or documented benefits over standard laparoscopic approaches have been reported for the pediatric population.

Competing interests: Dr. Moore is an investigator in clinical trials for Pfizer and Astellas. 


\section{References}

1. Khambati, MD; Elias Wehbi, MD; Walid A. Farhat, et al. Laparo-endoscopic single site surgery in pediatrics: Feasibility and surgical outcomes from a preliminary prospective Canadian experience. Can Urol Assoc J 2015;9(1-2):48-52. http://dx.doi.org/10.5489/cuaj.2379

2. Autorino R, Sosnowski R, De Sio M, et al. Laparo-endoscopic single-site surgery: Recent advances in urology. Central Eur J Urol 2012;65:204-11. http://dx.doi.org/10.5173/ceju.2012.04.art5

3. Merseburger AS, Herrmann TR, Shariat SF, et al. EAU guidelines on robotic and single-site surgery in urology. Eur Urol 2013;64:277-91. http://dx.doi.org/10.1016/i.eururo.2013.05.034

4. Fan $\mathrm{X}$, Lin $\mathrm{T}$, Xu K, et al. Laparoendoscopic single-site nephrectomy compared with conventional laparoscopic nephrectomy: A systematic review and meta-analysis of comparative studies. Eur Urol 2012;62:60112. http://dx.doi.org/10.1016/i.eururo.2012.05.055
5. Sanchez-Margallo FM, Matos-Azevedo AM, Perez-Duarte FJ, et al. Performance analysis on physical simulator of four different instrument setups in laparo-endoscopic single-site (LESS) surgery. Surgical Endosc 2014;28:1479-88. http://dx.doi.org/10.1007/s00464-013-3337-1

6. McCann ME, Soriano SG. General anesthetics in pediatric anesthesia: Influences on the developing brain. Curr Drug Targ 2012;13:944-51. http://dx.doi.org/10.2174/138945012800675768

Correspondence: Dr. Katherine Moore, Division of Urology, Centre Hospitalier Universitaire de Québec (CHUQ, CHUL), 2705, Boul. Laurier, R-1742, Québec, Québec, Canada, GIV 4G2; katherine.moore.1@ulaval.ca 